Bangladesh J. Bot. 50(3): 963-968, 2021 (September) SpecialＤOI: https://doi.org/10.3329/bjb.v50i5.56451

\title{
EFFECTS OF GLOBAL WARMING ON PLATEAU PLANTS
}

\author{
DAN Wu ${ }^{1}$ AND HuI KONG ${ }^{1}$ \\ Institute of Land Engineering and Technology, Shaanxi Land Engineering \\ Construction Group Co. Ltd., Xi'an 710075, China
}

Keywords: Global warming, Tibetan Plateau, Response mechanism, Diversity

\begin{abstract}
Biological and ecological environment in the plateau climate warming, abiotic environmental factors to different degrees of change were summed up from the macroscopic level to microcosmic individual physiological level of global climate change response model. The study summarized the research achievements at home and abroad, pointed out the plant phenology, photosynthesis, nutrient structure and presents different response patterns. These different response modes, from micro to macro, will eventually lead to changes in the structure and function of the Plateau ecosystem. This will threaten the survival and development of the Plateau plants on a large scale. Finally, the future research emphases in this field would be prospected.
\end{abstract}

\section{Introduction}

Climate change is a major problem facing the whole world in the 21st century (Qin et al. 2005), which has become an indisputable scientific fact. In particular, global warming has attracted much attention of the international community. The fifth assessment report of IPCC pointed out that the global surface temperature continues to rise, the global average temperature has increased by $0.85^{\circ} \mathrm{C}$ from 1880 to 2012 , in the northern hemisphere. Climate change is an important factor affecting the interannual variation of vegetation activities. Grassland, as the main body of terrestrial ecosystem, is very sensitive to climate change. Global climate change will inevitably cause changes in the growth environment of forage, and then affect the growth dynamics, structure and function of forage (Fang 2020). In the context of global climate change, the temperature in China has been increasing. In the past 50 years, the annual average surface temperature in China has increased by $1.1{ }^{\circ} \mathrm{C}$, which is significantly higher than that in the world (Sun and Wang 2010). The trend of precipitation change is not obvious, the decadal fluctuation is large, and there are obvious regional differences.

In the present study Plateau were reviewed with a system within the ecosystem response mechanism of plants to global warming. At the same time, combining with the researches of the Qinghai-Tibet plateau area in China some proposals are put forwarded on the development direction in the field of the study. Under the background of global warming, in-depth research, conservation and sustainable use of plateau biodiversity resources were used to provide the reference and basis.

It is well known that the increase in the concentration of greenhouse gases and the rise in atmospheric temperature are the most significant features of global warming. Compared to lowaltitude regions, the climate changes in plateau or high-altitude regions are more significant, especially in the aspects of temperature increase, precipitation pattern change and frequency of extreme climate events. Pepin and Seidel (2005) compared the global surface and atmospheric temperatures at high altitudes and concluded that the temperature increase at high altitudes has

*Author for correspondence: <843969970@qq.com>. ${ }^{1}$ Key Laboratory of Degraded and Unused Land Consolidation Engineering, the Ministry of Natural Resources, Xi'an 710075, China. 
been $0.13^{\circ} \mathrm{C} / 10$ a since the late 20th century. Researchers predict that the average temperature increase range of all Plateau regions in the world will be between $3.2^{\circ} \mathrm{C}\left(0.4^{\circ} \mathrm{C} / 10\right.$ a) and $2.1^{\circ} \mathrm{C}$ $\left(0.26^{\circ} \mathrm{C} / 10\right.$ a) by 2055 , much higher than that of low-altitude areas (Nogués-Bravo et al. 2007). Since the 20th century, the glacier area in the European Alps has decreased by 30-40\%, and the temperature of the permafrost has also changed significantly (IPCC 2007). In addition to glaciers, the area of snow cover on the plateau also shows a decreasing trend (Haeberli and Beniston 1998). In addition, glacier segmentation and the expansion of rock exposed area may lead to avalanches, landslides and debris flows and other natural disasters, which further threaten the stability of the plateau plant habitat (Holzinger et al. 2008).

The Qinghai-Tibet Plateau in China is a sensitive area of climate change, and its atmospheric temperature warming rate is about 3 times that of the global warming rate (Pan et al. 2001). It is worth noting that the warming of the Qinghai-Tibet Plateau began from the mid-1950s to the early 1960s, while the warming of other regions in the northern hemisphere began from the mid-1970s, which further highlights the high sensitivity of the Qinghai-Tibet Plateau to global climate change (Xu et al. 2007).

Influenced by climate, environment, terrain and other biological and abiotic factors, the Plateau ecosystem nurtures the world's most abundant plant diversity resources and ranks among the world's biodiversity hotspots (Hooper et al. 2005). Climate change has affected the species composition and community structure of Plateau ecosystem, which has both positive and negative effects on the maintenance of Plateau biodiversity. On the other hand, rising temperatures can cause more lowland or low-elevation species to migrate to higher elevations, thereby increasing species diversity at higher elevations to some extent. For example, Pauli et al. (1996) stated that plant species richness of 30 peaks in the European Alps increased by 70\% during 1992-1993 compared to historical records. The study confirmed that the plant diversity in the high native territory of Australia was closely related to soil temperature. For every $1{ }^{\circ} \mathrm{C}$ increase in soil temperature, the number of species increased by 7.3 on an average (Pickering et al. 2008). On the other hand, climate warming may also lead to the decrease of biodiversity in the plateau biosphere. Warming that alters plateau belt soil nutrition, increases soil organic matter, effective nitrogen and other nutrients. The original native plant species could adapt to the growth of the plateau in resource utilization efficiency and as a result of soil nutrients increase with the introduction of foreign plant species competition. Eventually it led to the plateau native plants or plant species in the group of special disappear or die (IPCC 2007).

Climate change directly reflects the structural changes of terrestrial ecosystems in terms of functions of terrestrial ecosystems. Nogues-Bravo et al. (2007) believed that under the background of current global climate change, alpine ecosystem may change into tropical component type (Becker et al. 2005). The findings of Yang and Piao (2006) in recent 20 years showed that grassland vegetation was significantly expanding, and the change of grassland vegetation was closely related to climate change. In addition to temperature, increased rainfall as a result of global climate change may also promote the growth of fast-growing grasses, thereby compressing the space for other plant life forms, such as shrubs, within their congenitals. In addition, $\mathrm{Lv}$ and $\mathrm{Wu}$ (2009) believed that under the condition of an increase in average temperature of $4{ }^{\circ} \mathrm{C}$ and an increase in annual precipitation of $10 \%$, the mountainous vegetation in the southeastern part of the Qinghai-Tibet Plateau would have an obvious trend of forestalization, and the forest area might increase by $6.4 \%$, especially the area of thermal and warm forests. The area of alpine meadows will decrease significantly and most of them will be transformed into mountain cold and warm coniferous forests. The area of alpine steppe decreased by more than half, and most of them turned into warm steppe. Although most of the alpine deserts in the western part of the Plateau are converted to warm deserts, they are compensated by the warming of frozen deserts and sub-snow 
and ice zones, and the warm deserts in the mountainous areas of the Plateau increase by about $14 \%$.

Plant phenology is defined as the time at which a plant species responds to seasonal dynamics. Plant phenology is closely related to climatic and environmental factors, and plant life cycle is also strongly influenced by temperature and precipitation (Danby and Hik 2007). Changes in plant phenology may be the simplest and most direct response of species in the ecosystem to climate change. Global warming has significantly altered the flowering phenology of plants, and this effect is particularly significant in polar and alpine ecosystems. For plants, the most significant phenological change is the advance of spring caused by temperature rise and early snowmelt, which leads to the advance of flowering and bearing time (Cleland et al. 2007). The results showed that early-flowering plants responded more quickly to climate warming during the flowering season than late-flowering plants. Other evidence also confirms that autumn phenology is delayed, but this pattern of change is not significant in some cases and is heterogeneous in species. For example, in the past 50 years in Europe, the time of leaf color changing was delayed by 0.3-0.6 d per decade. However, the average plant growing season has increased by $3.6 \mathrm{~d}$ per decade in some regions, and the average annual growing season in Europe has been extended by $10.8 \mathrm{~d}$ since 1960 .

Propagation of alpine plants is highly sensitive to temperature changes, and the whole life cycle of plants is controlled by temperature from flowering, bearing, seed formation to seed germination and seedling growth. Although different plant species have different responses to temperature, it can be seen from the general trend that temperature increase is helpful for plants to produce a higher proportion of mature seeds, improve seed germination rate, and contribute to the establishment of seedlings (Hedhly et al. 2009). In terms of extreme high temperature, the vast majority of plant species can only tolerate small temperature changes in the reproductive stage, and if the tolerance range is exceeded, the female and male fitness of plants will be affected. In the period of gamete formation, short-term high temperature stress will affect the number and shape of pollen, the structure of pollen wall, its chemical composition and metabolic characteristics of plants, resulting in a decline in the number of mature pollens, thus reducing the male fitness of plants, and indirectly affecting the production of fruits and seeds of plants (Erickson and Markhart 2002). On the other hand, high temperature can shorten the growth cycle of individual plant species and prolong the growth cycle of plant species or populations, and thus lead to the completion of the life cycle of many low-altitude plant species in high altitude regions. In addition, plants with special structures (such as thermal insulation structures) in the alpine region, such as Saussulia, have a special mechanism to adapt to the extreme periglacial environment in the alpine region, and the increase of temperature in the alpine region may also affect their reproduction.

Plant photosynthesis and the resulting processes of plant growth and biomass production are directly affected by temperature and atmospheric $\mathrm{CO}_{2}$ concentration. The response of plant photosynthesis in terrestrial ecosystems to the rise of global average temperature may lead to the change of carbon cycle and carbon balance in the ecosystem (Lorens et al. 2004). For alpine plants, some researchers believe that climatic characteristics such as low temperature and low atmospheric $\mathrm{CO}_{2}$ in alpine areas determine that the photosynthesis rate of alpine plants is lower than that of lowland plants. However, many studies have confirmed that the photosynthetic rate of alpine plant species is roughly the same as that of lowland plants, and attributed this to the fact that alpine plants maintain normal photosynthesis by increasing stomatal conductance and adjusting the position of leaves (Niu et al. 2008). Although many studies have focused on the effects of global climate change on plant biomass production and growth processes at high altitudes and latitudes, few studies have reported the direct relationship between global warming 
and photosynthesis in alpine plants. In the case of lowland plants, climate warming can affect photosynthesis directly or indirectly through water stress caused by warming. On the other hand, the increase of temperature may not affect plant photosynthesis. The above inconsistencies may be caused by the species heterogeneity of plant photosynthesis in response to climate warming. In addition, the heterogeneity of the response of plant photosynthesis to external environmental changes may also lead to changes in carbon accumulation, plant growth and biomass production among different plant species, which in turn will lead to changes in plant competitiveness, coverage and dominance in the community. Similarly, alpine plant species exhibit similar species heterogeneity in response to environmental or climate change. Therefore, under the background of climate change, some alpine plant species or plant life forms may gain more benefits, which will lead to the changes of plant species relationships, plant community structure and composition, and ultimately affect the stability of alpine ecosystem.

The invasion of alien species of plants refers to the phenomenon that plants grow and reproduce in different places under the natural state or under the action of human beings. Under climate change, alien species in adjacent areas are likely to cross geographical barriers and become new components of the local biota. The change of environment and climate factors caused by climate change has undoubtedly created conditions for the migration and successful settlement of alien species. The high selective filtration of temperature and other environmental and climatic factors in alpine regions makes it difficult for non-native plant species, especially those at lower elevations, to grow, reproduce and complete their life histories in the region. The influx of a large number of lowland or low-altitude plant species will greatly compress the limited living space of alpine native plants, leading to the invasion or migration of alpine native plants to higher elevations, and eventually lead to the extinction of alpine native plants (Klanderud and Birks 2003), which has completed another form of biological invasion. Upward migration of lowland plants has been found to be common in many high altitude and high latitude regions. For example, Johnston and Pickering (2001) found that the diversity and richness of exotic plants in the Australian Alps have greatly increased in recent years. Similar results have been found in the Swiss Alps (Becker et al. 2005). Climate warming has caused significant changes in alpine habitats, and the evolution rate of plant tolerance to climate change is much slower than the rate of climate change. As a result, some alpine plants will either die directly or migrate to higher altitudes. However, the higher the species migration, the smaller the population size and the smaller the distribution area, and the increasing environmental and selection pressure. When the species retreat to the top of the mountain and become "no way out", they also face the danger of extinction.

The global warming trend is still accelerating, and there is no doubt that climate change must be the most important environmental factor leading to the change of alpine habitat, as well as one of the most important evolutionary driving forces leading to the change of alpine plant biological characteristics. The Global Alpine Eco-environmental Observation and Research Program have established 36 observation sites on 135 mountain peaks worldwide to obtain standardized data on alpine biodiversity and vegetation patterns, and a number of studies have been made. In the Qinghai-Tibet Plateau of China, especially in some extreme high-altitude habitats, there is still a lack of research on the response mechanism of plant adaptation and evolution at all levels to climate warming. However, it is Difficult to provide a reliable scientific basis for the establishment of protection and early warning mechanisms in the corresponding regions. The response of the plant species on the Qinghai Tibet plateau to climate change and adaptation mechanisms of scientific questions should focus on the following aspects: (i) under the background of climate warming, alpine plants species in the acquisition, allocation and utilization of resources way aspect may change, and the possible impact of plant community and ecosystem; (ii) Studies on 
reproductive characteristics of alpine plants include pollination process, embryo and seed formation, seed dispersal, etc; (iii) Studies on functional traits of alpine plants are morphological and physiological characteristics formed by long-term selective evolution of plants to adapt to environmental changes; (iv) Studies on the relationship between complex relationships among individual plants, among species and among communities which are the prerequisites for maintaining a healthy and stable ecosystem.

Use of the response rules of plants and climate factors in the Qinghai-Tibet Plateau can provide reference and basis for improving the life span of plants in the region and protecting the ecosystem of the Qinghai-Tibet Plateau. Long-term studies in the future will reveal the underlying causes that cause and limit changes in plant distribution patterns on the Qinghai-Tibet Plateau, and also provide a strong scientific basis and guarantee for the formulation of targeted conservation measures to deal with global change.

\section{Acknowledgements}

This research was supported by Scientific Research Item of Shaanxi Provincial Land Engineering Construction Group No. DJNY2021-32 and DJNY2019-29.

\section{References}

Becker T, Dietz H, Billeter R, Buschmann H and Edwards PJ 2005. Altitudinal is tribution of alien plant species in the Swiss Alps. Perspect Plant Ecol. 7: 173-183.

Cleland EE, Chuine I, Menzel A, Mooney HA and Schwartz MD 2007. Shifting plant phenology in response to global change. Trends Ecol. Evol. 22: 357-365.

Danby RK and Hik DS 2007. Variability, contingency and rapid change in recent ubarctic alpine tree line dynamics. J. Ecol. 95: 352-363.

Erickson AN and Markhart AH 2002. Flower developmental stage and organ sensitivity of bell pepper (Capsicum annum L.) to elevated temperature. Plant Cell Environ. 25: 123-130.

Fang JY 2020. Global ecology: climate change and ecological responses. Beijing: Higher Education Press, 2000: 319.

Hedhly A, Hormaza, JI and Herrero M 2009. Global warming and sexual plant reproduction. Trends Plant Sci. 14(1): 30-36.

Haeberli W and Beniston M 1998. Climate change and its impacts on glaciers and permafrost in the Alps. Ambio. 27: 258-265.

Holzinger B, Hülber K, Camenisch M and Grabherr G 2008. Changes in plant species richness over the last century in the eastern Swiss Alps: Elevational gradient, bedrock effects and migration rates. Plant Ecol. 195: $179-196$.

Hooper DU, Chapin FS III, Ewel JJ, Hector A, Inchausti P, LavorelS, Lawton JH, Lodge DM, Loreau M, Naeem S, Schmid B, SetätäH, Symstad AJ, Vandermeer J and Wardle DA 2005. Effects of biodiversity on ecosystem functioning: A consensus of current knowledge. Ecol. Monogr. 75(1): 3-35.

IPCC 2007. Climate Change 2007. The physical science basis. The fourth assessment report of working group. Cambridge, UK: Cambridge University Press.

Johnston FM and Pickering CM 2001. Alien plants in the Australian Alps. Mt. Res. Dev. 21: 284-291.

Klanderud K and Birks HJB 2003. Recent increases in species richness and shifts in altitudinal distributions of Norwegian mountain plants. Holocene 13: 1-6134.

Lorens L, Penuelas J, Beier C, Emmett B, Estiarte M and Tietema A 2004. Effects of an experimental increase of temperature and drought on the photosynthetic performance of two ericaceous shrubs species along a North-South European gradient. Ecosystems 7: 613-624.

Lv JJ and Wu JG 2009. Advances in the effects of climate change on the distribution of plant species and vegetation in China. Environ. Sci. Technol. 32 (6): 85-95. 
Niu SL, Li ZX, Xia JY, Han Y, Wu MY and Wan SQ 2008. Climatic warming changes plant photosynthesis and its temperature dependence in a temperate steppe of northern China. Environ. Exp. Bot. 63: 91-101.

Nogués-Bravo D, Araújo MB, Errea MP and Martínez-Rica JP 2007. Exposure of global mountain systems to climate warming during the 21st century. Global Environ Change 17: 420-428.

Pan YD, Melillo JM, Kicklighter DW, Xiao XM and Mcguire AD 2001. Modeling structural and functional responses of terrestrial ecosystems in China to changes in climate and atmospheric $\mathrm{CO}_{2}$. Acta Phytoecol Sin. 25(2):175-189.

Pauli H, Gottfried M and Grabherr G 1996. Effects of climate change on mountain ecosystems-upward shifting of alpine plants. World Resour Rev. 8: 382-390.

Pepin NC and Seidel DJ 2005. A global comparison of surface and free air temperatures at high elevations. J. Geophys. Res. 110: D03104.

Pickering C, Hill W and Green K 2008. Vascular plant diversity and climate change in the alpine zone of the Snowy Mountains, Australia. Biodiv. Conserv. 17: 1627-1644.

Qin DH, Ding YH, Su JL, Su JL, Ren Jw, Wang SW, Wu RS, Yang XQ, Wang SN, Liu SY, Dong GG, Lu Q, Huang ZG, Du BL and Luo Y 2005. Assessment of climate and environmental change in China (I): climate and environmental change and future trends in China. Climate Change Res. 1(1): 4-9.

Sun ZH and Wang CY 2010. Effects of climate change on Agriculture in China. Science and Technology Review 4:110-117.

Xu ZX, Zhang L, Huang JX and Gong TL 2007. Long-term trend of temperature, precipitation and relative humidity in The Tibetan region. Meteorol. Mon. 33: 37-43.

Yang YH and Piao SL 2006. Variations in grassland vegetation cover in relation to climatic factors on the Tibetan Plateau. Plant Ecol. 30 (1): 1-8.

(Manuscript received on 19 May, 2021; revised on 29 September, 2021) 